This item was submitted to Loughborough's Research Repository by the author.

Items in Figshare are protected by copyright, with all rights reserved, unless otherwise indicated.

\title{
High temperature stability of broadband Anti-Reflection coatings on soda lime glass for solar modules
}

PLEASE CITE THE PUBLISHED VERSION

http://dx.doi.org/10.1109/PVSC.2015.7356265

PUBLISHER

(C) IEEE

VERSION

AM (Accepted Manuscript)

\section{PUBLISHER STATEMENT}

This work is made available according to the conditions of the Creative Commons Attribution-NonCommercialNoDerivatives 4.0 International (CC BY-NC-ND 4.0) licence. Full details of this licence are available at: https://creativecommons.org/licenses/by-nc-nd/4.0/

\section{LICENCE}

CC BY-NC-ND 4.0

\section{REPOSITORY RECORD}

Womack, Gerald, Piotr M. Kaminski, and Michael Walls. 2019. "High Temperature Stability of Broadband Antireflection Coatings on Soda Lime Glass for Solar Modules”. figshare. https://hdl.handle.net/2134/20082. 


\title{
High Temperature Stability of Broadband Anti-Reflection Coatings on Soda Lime Glass for Solar Modules

\author{
G. Womack ${ }^{1,2}$, P.M. Kaminski ${ }^{2}$, J.M. Walls ${ }^{2}$
}

\author{
${ }^{1}$ National Structural Integrity Research Centre (NSIRC Ltd.), Granta Park, Great Abington, \\ Cambridge, CB21 6AL, United Kingdom
}

\begin{abstract}
${ }^{2}$ CREST (Centre for Renewable Energy Systems and Technology), School of Electronic, Electrical and Systems Engineering, Loughborough University, Loughborough, LE11 3TU, United Kingdom
\end{abstract}

\begin{abstract}
Reflections from glass surfaces reduce the efficiency of photovoltaic devices. Reflections can be reduced using a broadband Multi-layer Anti-Reflection (MAR) coating. For thin film CdTe modules, the glass is also the substrate. Manufacturers would prefer to use pre-MAR coated glass, so it is essential to establish if the MAR coating can withstand the module production process conditions. Thin film CdTe module fabrication requires temperatures up to $\sim 500^{\circ} \mathrm{C}$. Crazing may occur due to mismatch of the thermal expansion coefficients between the glass and the coating materials. The resilience of MAR coatings on soda lime glass, Eagle $2000^{\mathrm{TM}}$ Glass, and NSG TEC 7 has been tested by exposure to increasing temperatures up to $800^{\circ} \mathrm{C}$ to establish the point of failure. SEM imaging and reflection measurements were used to observe the damage caused. Surprisingly, the MAR coating is unaffected up to a temperature of $590^{\circ} \mathrm{C}$ on soda lime glass substrates and up to $800^{\circ} \mathrm{C}$ on Eagle Glass. This provides confidence that thin film CdTe module manufacturers can use existing processes with pre-MAR coated glass.
\end{abstract}

Index Terms - Anti-Reflective, AR, Coating, Heat Treatment, Sputtering.

\section{INTRODUCTION}

Thin film CdTe photovoltaics (PV) modules are currently the most important second generation thin film PV technology. A thin film CdTe solar cell with a record efficiency of $21.5 \%$ has been reported recently by First Solar Inc.[1]. Commercially available modules presently have efficiencies $\sim 13 \%$, with a $17.5 \%$ world record for module efficiency reported [1]. Thin film CdTe solar cells are usually deposited using Closed Space Sublimation (CSS) or the Vapour Transport Deposition (VTD) method. The CdS and CdTe thin films, which form the p-n heterojunction, are usually deposited on a transparent conducting oxide coated glass superstrate using a high temperature process. The deposition of the heterojunction is followed by a cadmium chloride $\left(\mathrm{CdCl}_{2}\right)$ activation treatment at $\sim 400^{\circ} \mathrm{C}$ and then by the formation of the back contact.

A typical thin film CdTe solar cell with an efficiency of $\sim 13 \%$ delivers a short circuit current density of $\sim 22.5$ $\mathrm{mA} / \mathrm{cm}^{2}$ [2]. However, the AM1.5G spectrum (between 350 $\mathrm{nm}$ and $850 \mathrm{~nm}$ wavelengths) should enable current densities of up to $31.2 \mathrm{~mA} / \mathrm{cm}^{2}$. The current density losses in CdTe devices can be attributed to optical effects. The two most significant loss mechanisms are the optical absorption in the n-type CdS window layer and the reflection losses from the glass substrate. The absorption losses in the CdS can be controlled by minimising the thickness of the CdS layer.

The light reflection losses occur due to the refractive index mismatch between the module glass and air. This mismatch leads to reflection losses of $\sim 4.2 \%$. The reflection from the glass substrate can be reduced by application of an anti-reflection coating [3]-[5]. Use of a broadband MultiLayer Anti-Reflection (MAR) Coating is the most effective solution to this problem. The MAR coatings offer the highest reduction in reflection, excellent durability and low cost [3]. The design of the MAR coatings for thin film CdTe has been described elsewhere [3]. The design of these MAR coatings is based on the use of high/low refractive index material pairs. We used $\mathrm{ZrO}_{2}$ as the high index material and $\mathrm{SiO}_{2}$ as the low index material. Four layer alternate $\mathrm{ZrO}_{2} / \mathrm{SiO}_{2}$ MAR coatings deposited by pulsed DC Magnetron sputtering have been investigated in this study. The refractive index change within the MAR stack combined with a precise control of layer thickness takes advantage of destructive light interference to minimize the reflection losses. These dielectric metal-oxide materials are hard and scratch resistant and adhere well to glass surfaces. Their durability and environmental stability is exceptional and already well proven in ophthalmic and precision optical applications even on plastic substrates [6].

In the manufacture of thin film CdTe modules the glass acts as the substrate for the PV device deposition. Although it is feasible to deposit the MAR coating as the final step in module fabrication this would involve the addition of another process step and further capital expenditure. Sourcing pre-coated MAR glass is a more attractive commercial proposition. However, the MAR coating is then exposed to significant high temperatures during the deposition of the absorber layer and during the cadmium chloride activation step. The glass temperature during these processes is typically in the range $400^{\circ} \mathrm{C}$ [7] to $500^{\circ} \mathrm{C}$ [8].

These types of MAR coatings have been tested previously for optical applications. In these studies, using ISO and IEC accelerated lifetime testing protocols, the coatings have demonstrated excellent durability [6], [9]. However, none of these previous tests have tested durability using temperatures above $100^{\circ} \mathrm{C}$. 
At higher temperatures there is a risk that the coating will craze due to the mismatch in thermal expansion coefficients between the materials used in the thin film multilayer stack and the glass substrate. Crazing of the coating could result in a performance decrease and could lead to a complete coating delamination. Cracks in the coating allow water penetration which significantly reduces the lifetime of the MAR coating. The deposited MAR coatings were tested by exposure to high temperatures in a baffle furnace. The temperature was increased from room temperature to $600^{\circ} \mathrm{C}$ on soda lime glass and to $800^{\circ} \mathrm{C}$ on high temperature Eagle glass to establish the point of failure. Scanning Electron Microscopy (SEM) and spectroscopic reflection measurements were used to observe the effects of increasing the temperatures on the coating.

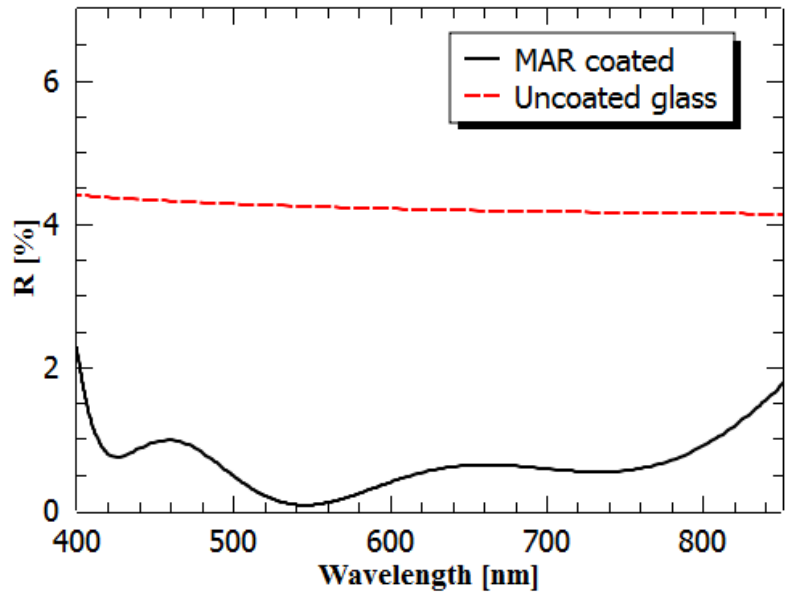

Fig. 1 Modelled reflectance spectrum of as deposited four layer $\mathrm{ZrO}_{2} / \mathrm{SiO}_{2}$ MAR coating (black line), and uncoated glass (red line), corrected to exclude back surface reflectance.

\section{EXPERIMENTAL}

Multi-layer anti-reflection Coatings were deposited using pulsed DC magnetron sputtering in a "PV Solar" deposition system supplied by Power Vision Ltd., (Crewe, UK). The system was designed for multilayer thin film deposition and is equipped with up to four $150 \mathrm{~mm}$ circular magnetrons mounted vertically around a cylindrical chamber. The system allows deposition of multi-layer stacks under computer control. One of the magnetrons can be replaced with a plasma source for reactive sputtering.

The $5 \mathrm{~cm} \times 5 \mathrm{~cm}$ glass substrates ( $1 \mathrm{~mm}$ thick) were cleaned using a 30 min wash in an ultrasonic bath using a $10 \%$ IPA solution in de-ionised (DI) water (18 M $\Omega-\mathrm{cm})$. This was followed by a rinse in DI water and drying using dry compressed air. The substrates were then mounted vertically on a rotatable carrier. The carrier rotates typically at 120rpm during the deposition process to provide coating uniformity. Two magnetrons are fitted with silicon and zirconium planar metallic targets. A thin layer of metal is deposited in each pass of the carrier. An $800 \mathrm{~V}$ DC power supply is used to maintain an oxygen plasma from a source located at a third position. This allows the metal films to be converted into the optical quality metal-oxides required for the MAR design. The metal layers were sputtered using a pulsed DC power supply (Advanced Energy Inc. Pinnacle plus $5 \mathrm{~kW}$ ) in an argon/oxygen environment. The zirconium was sputtered at $1 \mathrm{~kW}$ using a $1.5 \mu$ s reverse time, while the silicon was deposited at $1.5 \mathrm{~kW}$ and a $2.5 \mu$ s reverse time. The frequency of the pulse was set to $150 \mathrm{kHz}$ for both materials. The strategy of separating metal deposition from the oxidation process in separate zones avoids reactive sputtering hysteresis effects and also allows high deposition rates to be obtained [10], [11]. Since the sputtering rate of metals is stable, the layer thickness can be controlled accurately using time only under computer control. A quartz crystal monitor is not required.

The performance of the as-deposited anti-reflection coatings was tested by measuring the light reflection spectrum using a Varian Cary 5000 UV-Vis-NIR spectrophotometer. The reflection was measured for wavelengths between $350 \mathrm{~nm}$ and $850 \mathrm{~nm}$, with a $1 \mathrm{~nm}$ interval. The performance of the coating was assessed by calculating the weighted average reflection (WAR) from the spectrophotometer data and the AM1.5 solar spectrum. This method gives a representative reflection percentage from the MAR coated surface as it takes into account the relative abundance of photons at each wavelength. This range was chosen since given the $1.45 \mathrm{eV}$ band gap of CdTe only this wavelength range contributes to the photocurrent of the CdTe solar cells.

Due to the reflection from the back surface of the glass substrate, the reflection data gathered from the spectrophotometer is artificially high. WAR data quoted in tables 1 and 2 has had the back surface reflection removed to give a more accurate numerical representation of the MAR coating performance. The back surface reflection is still included in Fig. 6, Fig. 10, and Fig. 13.

Following the MAR deposition the coatings were exposed to temperatures between $100^{\circ} \mathrm{C}$ and $800^{\circ} \mathrm{C}$ at $10^{\circ} \mathrm{C}$ intervals. The heating of the coatings was performed for 30 minutes in a muffle furnace (Vecstar PF4). During the experiment the furnace was first pre-heated to the appropriate temperature and then the sample was placed on a small porous aluminasilicate brick support and then loaded into the furnace. The furnace was allowed to return to the set temperature. After the heat treatment was finished the brick with the sample was extracted. The coated glass substrate was then gently transferred from the hot brick onto a cool brick to allow cooling in air.

The impact of the high temperature exposure on the coating integrity was analysed using optical and SEM imaging of the surface. Reflection measurements were also taken to investigate the performance of the coating after the high temperature exposure.

Additionally Scanning White Light Interferometry, in particular coherence correlation interferometry (CCI); was used to measure the effect of heat treatment on the surface roughness and surface form of the samples. The roughness was assessed through comparison of the root mean square (RMS) roughness. [12]

\section{RESULTS}

In this paper three types of substrate have been investigated: Soda lime glass, Eagle glass (EG), and TEC 7. The WAR on uncoated soda lime glass was $4.23 \%$, for nonheated MAR the WAR was 1.6\%; a reflection decrease of $2.63 \%$. Fig. 1 shows the modelled reflection of the as deposited MAR coating used in this study. The 
measurements also confirmed excellent repeatability between the samples.

Variations in the WAR of as deposited samples are small and are caused by variations in the deposition conditions; the standard deviation of WAR of samples on Eagle glass, and TEC 7 is 0.077 , and 0.073 percentage points respectively showing excellent reproducibility.

\section{A. Soda-Lime Glass}

Fig. 2 Shows SEM images of the surface of four MAR coated glass substrates; as deposited and then heat treated for $30 \mathrm{~min}$ at $200^{\circ} \mathrm{C}, 400^{\circ} \mathrm{C}$ and $500^{\circ} \mathrm{C}$. The images show that the surface of the as deposited samples was smooth and defect free. The surface was not damaged due to the exposure of the glass even up to $580^{\circ} \mathrm{C}$. The reflection measurements confirmed that the optical properties of the coatings remained unchanged.

The lowest temperature that caused signs of slight crazing to appear was $590^{\circ}$, in the form of isolated fissures in the surface of the MAR. An example of these fissures can be seen in Fig. 4. Fig. 5 shows an optical image of a coating exposed to a temperature of $600^{\circ} \mathrm{C}$. Comparison with Fig. 3 shows that at $600^{\circ} \mathrm{C}$ the coating has crazed completely.
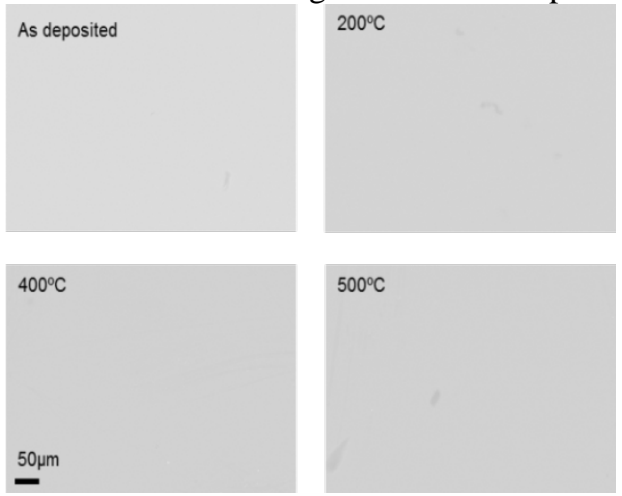

Fig. 2 SEM surface images of the as deposited MAR coated surface and surfaces exposed to temperatures of $200^{\circ} \mathrm{C}, 400^{\circ} \mathrm{C}$ and $500^{\circ} \mathrm{C}$. No crazing is observed.

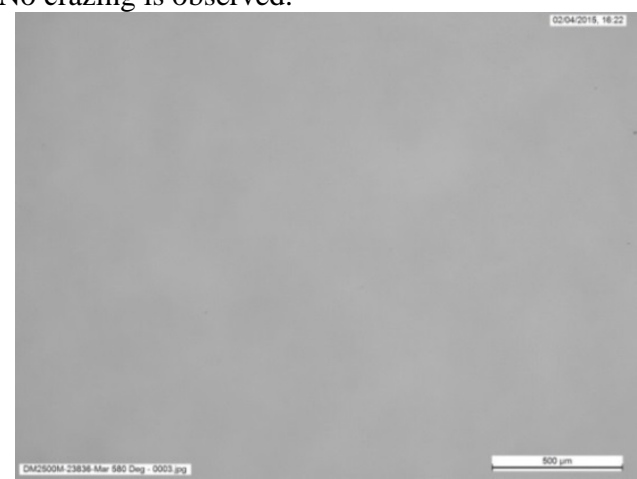

Fig. 3 An optical microscope image of MAR sample exposed to $580{ }^{\circ} \mathrm{C}$ for 30 minutes, showing no visible damage.

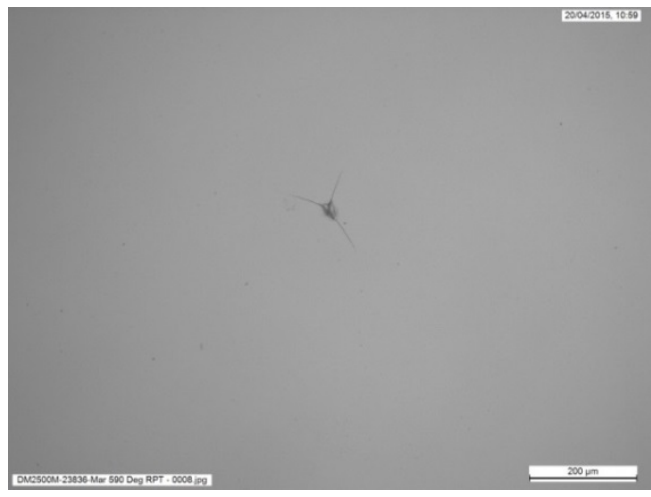

Fig. 4 Optical microscope images of MAR sample exposed to $590^{\circ} \mathrm{C}$ for 30 minutes, showing an isolated fissure in the surface of the coating.

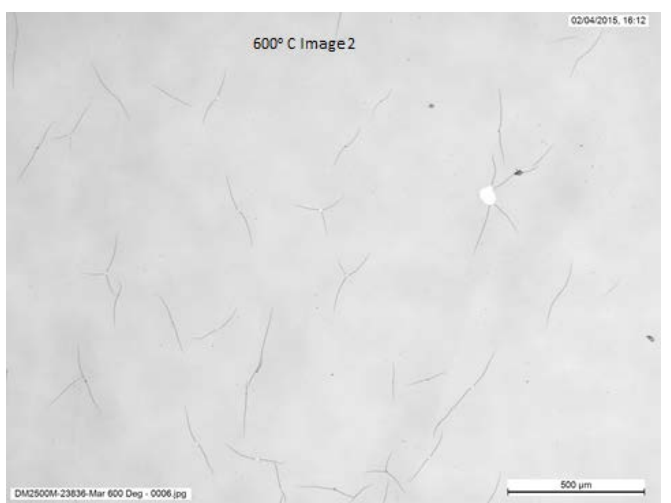

Fig. 5 Optical microscope image of MAR sample exposed to $600^{\circ} \mathrm{C}$ for 30 minutes revealing the occurrence of mild crazing.

A comparison of the reflectance of MAR coated glass after heat treatment at $500^{\circ} \mathrm{C}, 590^{\circ} \mathrm{C}$ and $600^{\circ} \mathrm{C}$ can be seen in Fig.6. The reflectance in terms of WAR for uncoated soda lime glass was $4.23 \%$, for as deposited MAR the WAR was $1.61 \%$, exposed to $500^{\circ} \mathrm{C}$ the WAR was $1.59 \%$, exposed to $590^{\circ} \mathrm{C}$ the WAR was $1.41 \%$, and exposure to $600^{\circ} \mathrm{C}$ the WAR was $1.36 \%$. This suggests that heat treatment has a negligible effect on the WAR of the samples.

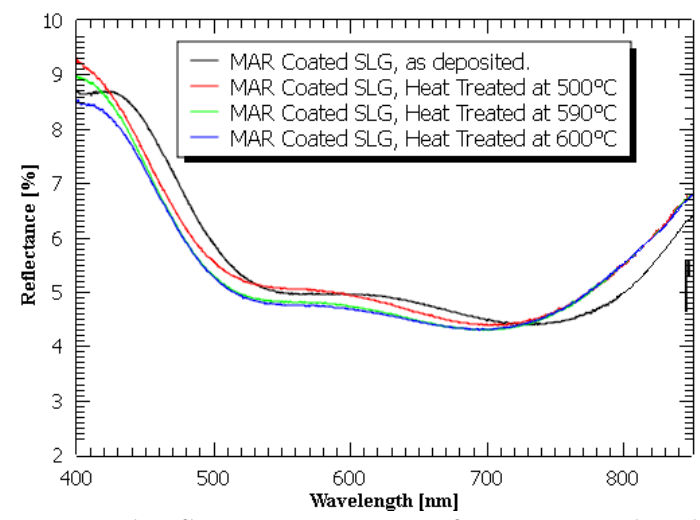

Fig. 6 Measured reflectance spectrum of MAR coated soda lime glass (SLG)(black line) and MAR coated glass heat treated to $500^{\circ} \mathrm{C}$ (red line), $590^{\circ} \mathrm{C}$ (green line) and $600^{\circ} \mathrm{C}$ (blue line), including back surface reflectance.

Fissures are produced in the surface of the MAR samples only after the soda lime glass has begun to warp due to the heat. Fig 7 provides a series of CCI images showing that the shape of the substrate changes depending on temperature. The corners curl up significantly, at this point the coating 
crazes and RMS roughness begins to increase. Experiments on Eagle glass were carried out to investigate the effect of using a high temperature glass substrate with a lower coefficient of thermal expansion on the surface roughness of the coating after heat treatment.

A. CCI Image of as deposited sample.

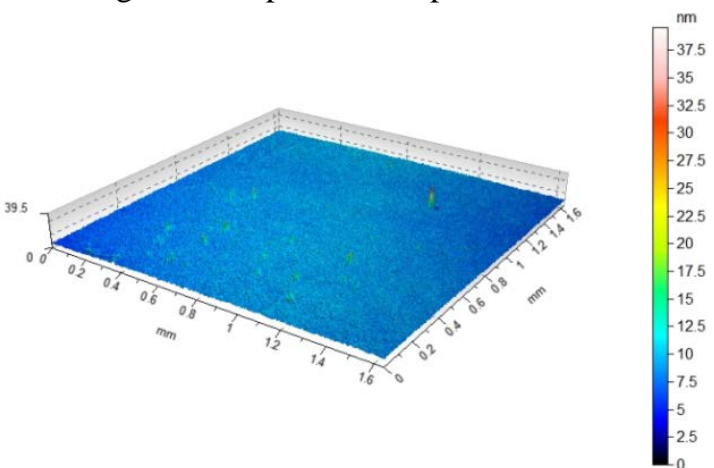

B. CCI Image of MAR sample on SLG exposed to $500^{\circ} \mathrm{C}$.

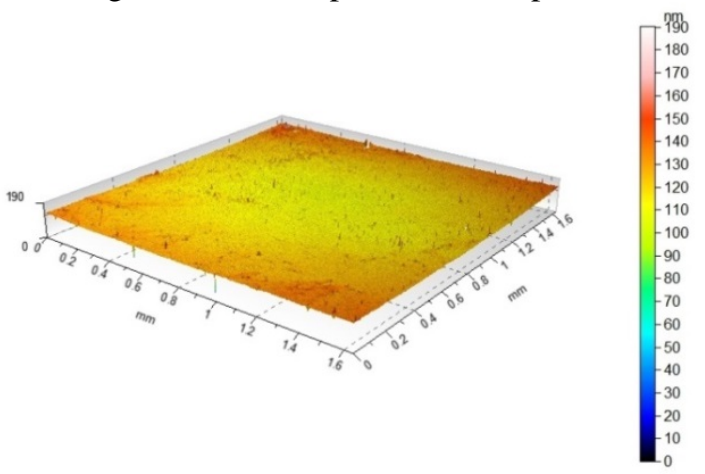

C. CCI Image of MAR sample on SLG exposed to $600^{\circ} \mathrm{C}$

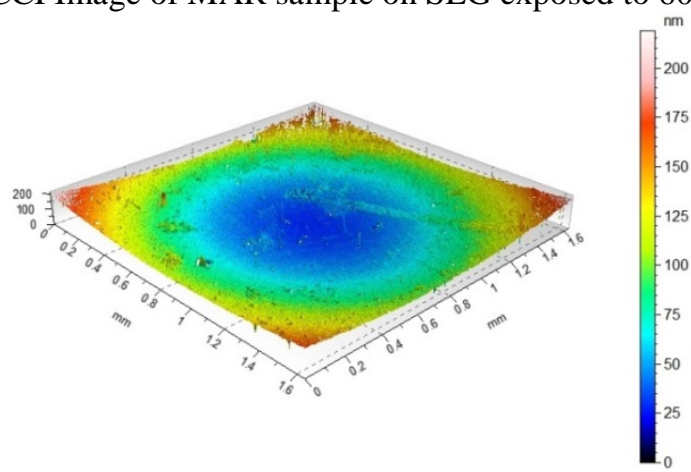

Fig. 7 CCI images of MAR samples. A: As deposited. B: Heat treated at $500^{\circ} \mathrm{C}$. C: Heat treated at $600^{\circ} \mathrm{C}$.

\section{B. Pilkington TEC 7 Glass}

Fig. 8 shows a comparison of the surfaces of MAR coatings deposited onto Pilkington TEC 7 glass after heat treatment at $500^{\circ} \mathrm{C}, 580^{\circ} \mathrm{C}, 590^{\circ} \mathrm{C}$, and $600^{\circ} \mathrm{C}$. Again the images show that the surface of the as deposited samples was smooth and defect free and the samples show no sign of crazing under SEM imaging. As the soda lime glass used in TEC7 is 3mm thick the glass warped less at temperatures approaching $600^{\circ} \mathrm{C}$ than the $1 \mathrm{~mm}$ thick soda lime glass samples. Slight crazing could only be found at the edges of the sample at temperatures above $590^{\circ} \mathrm{C}$. This supports the view that crazing in the coating is primarily caused by the mechanical movement of the substrate as it approached its melting point. An optical image of crazing at $590^{\circ} \mathrm{C}$ is shown in Fig. 9.

The Transparent conducting oxide (TCO) on the opposing side of the glass to the MAR was unaffected by the heat treatment as inspection at all temperatures showed no signs of crazing. However the TCO did soil as the surface was placed face down in the oven to preserve the MAR, increasing the measured WAR slightly.
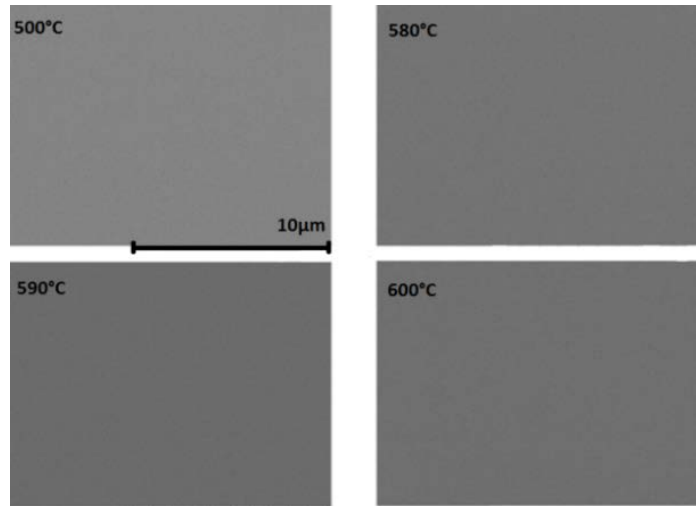

Fig. 8 SEM surface images of the central area of MAR coatings deposited on TEC 7 and then exposed to temperatures of $500^{\circ} \mathrm{C}$ (top left), $580^{\circ} \mathrm{C}$ (top right), $590^{\circ} \mathrm{C}$ (bottom left) and $600^{\circ} \mathrm{C}$ (bottom right). The coatings show no signs of crazing.

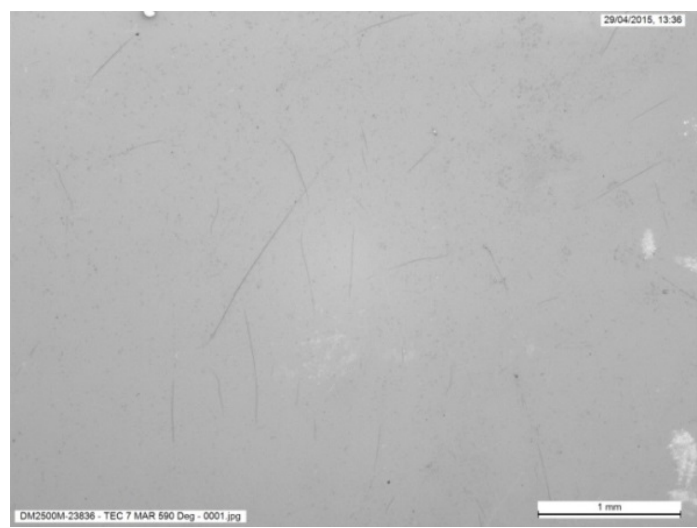

Fig. 9 Optical microscope image of an MAR coating deposited on TEC 7 and exposed to $590^{\circ} \mathrm{C}$ for 30 minutes showing very mild crazing at the warped edges of the glass.

A comparison of the reflectance of MAR coated TEC 7 glass after heat treatment at $500^{\circ} \mathrm{C}, 590^{\circ} \mathrm{C}$ and $600^{\circ} \mathrm{C}$ is shown in Fig.11. The reflectance in terms of WAR for nonheat treated MAR on TEC 7 was measured at $1.45 \%$. Samples before and after heat treatment showed negligible difference in WAR.

Table 1 Comparison of WAR of samples on TEC 7 before and after heat treatment at different temperatures. Numbers exclude back surface reflection.

\begin{tabular}{lll}
\hline $\begin{array}{l}\text { Heat treatment } \\
\text { temperature }\left[{ }^{\circ} \mathbf{C}\right]\end{array}$ & $\begin{array}{l}\text { WAR As } \\
\text { Deposited [\%] }\end{array}$ & $\begin{array}{l}\text { WAR Post } \\
\text { Treatment[\%] }\end{array}$ \\
\hline 500 & 1.46 & 1.72 \\
580 & 1.45 & 1.46 \\
590 & 1.47 & 1.60 \\
600 & 1.38 & 1.73 \\
\hline
\end{tabular}




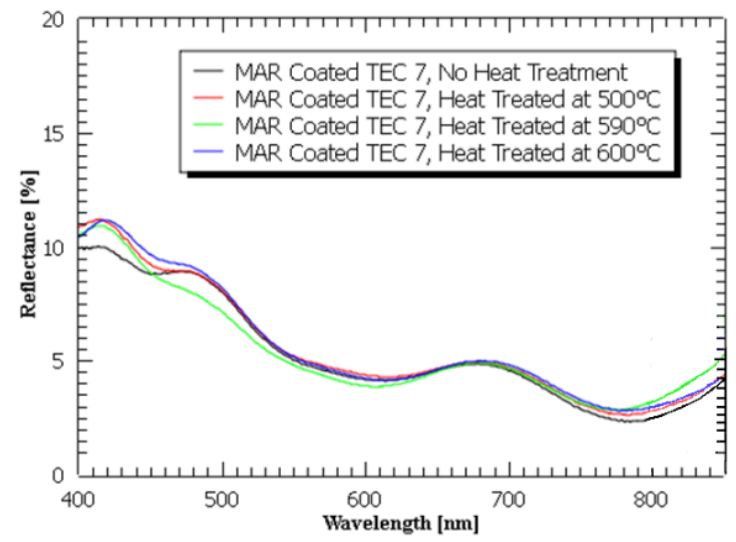

Fig. 10 Measured reflectance spectrum of as deposited MAR on TEC 7 glass (black line), and MAR coated glass heat treated to $500^{\circ} \mathrm{C}$ (red line), $590^{\circ} \mathrm{C}$ (green line) and $600^{\circ} \mathrm{C}$ (blue line), including back surface reflectance.

\section{Corning Eagle Glass}

To distinguish whether the AR coating on soda lime glass crazes due to the heat treatment or the deformation of the substrate, we repeated the tests using Corning Eagle Glass ${ }^{\mathrm{TM}}$. The annealing point of a glass is the temperature at which the glass is still hard to deform but has been softened enough to allow for stresses to relax within the glass. Eagle glass has an annealing point of $722^{\circ} \mathrm{C}$, allowing for greater temperature heat treatment compared to soda lime glass which has an annealing point of $546^{\circ} \mathrm{C}$.

Fig. 11 shows a comparison of the surfaces of MAR coatings deposited onto Eagle glass after heat treatment at $590^{\circ} \mathrm{C}, 600^{\circ} \mathrm{C}$, and $700^{\circ} \mathrm{C}$. The images show that the surface of the as deposited samples was smooth and defect free and the samples show no sign of crazing. Reflection measurements from the spectrophotometer show that heat treatment has a negligible effect on the WAR of the coated samples.

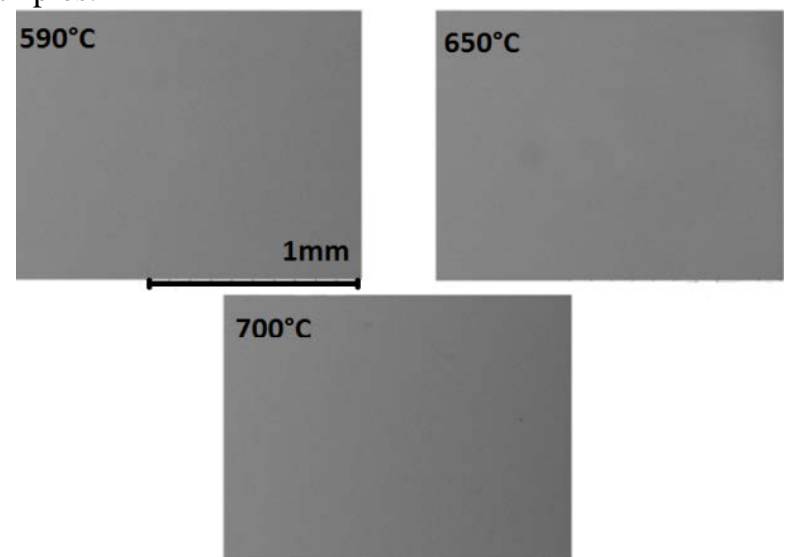

Fig. 11 SEM surface images of samples deposited on Eagle Glass exposed to temperatures of $590^{\circ} \mathrm{C}, 650^{\circ} \mathrm{C}$ and $700^{\circ} \mathrm{C}$. The samples show no signs of crazing.

Fig. 12 shows an optical image of a coating exposed to a temperature of $800^{\circ} \mathrm{C}$. Comparison with Fig. 11 shows that at $800^{\circ} \mathrm{C}$ the coating has begun to craze. However, only small examples of fissures in the coatings surface are observed at this stage. This difference in the damage compared with soda lime glass is due to the comparatively higher annealing point, higher melting point, and lower coefficient of thermal expansion of Eagle glass.

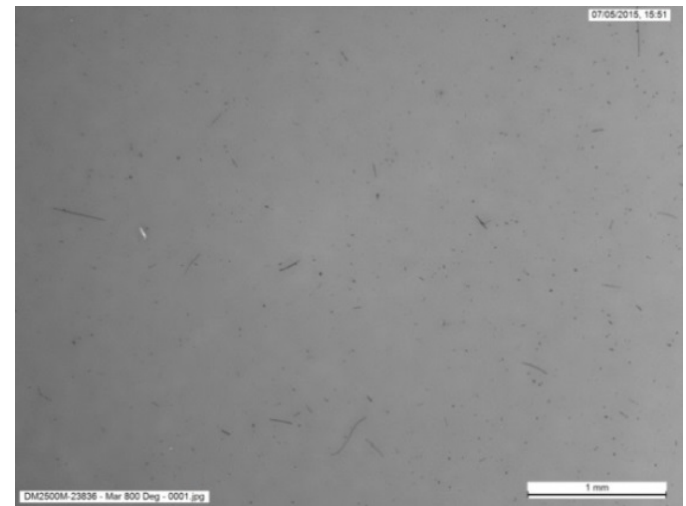

Fig. 12 Optical microscope images of MAR sample deposited on Eagle glass exposed to $800^{\circ} \mathrm{C}$ for 30 minutes, revealing mild crazing.

A comparison of the reflectance of MAR coated Eagle glass as deposited and after heat treatment at $590^{\circ} \mathrm{C}, 700^{\circ} \mathrm{C}$, and $800^{\circ} \mathrm{C}$ can be seen below in Fig.14. The reflectance in terms of WAR for untreated MAR on Eagle glass was measured at $1.76 \%$. The WAR after heat treatment can be seen in table 2 .

Table 2 Comparison of WAR of samples on EG before and after heat treatment at different temperatures.

\begin{tabular}{lll}
\hline $\begin{array}{l}\text { Heat treatment } \\
\text { temperature }\left[{ }^{\circ} \mathbf{C}\right]\end{array}$ & $\begin{array}{l}\text { WAR As } \\
\text { Deposited [\%] }\end{array}$ & $\begin{array}{l}\text { WAR Post } \\
\text { Treatment[\%] }\end{array}$ \\
\hline 590 & 1.76 & 1.70 \\
650 & 1.71 & 1.62 \\
700 & 1.89 & 1.77 \\
800 & 1.76 & 1.50 \\
\hline
\end{tabular}

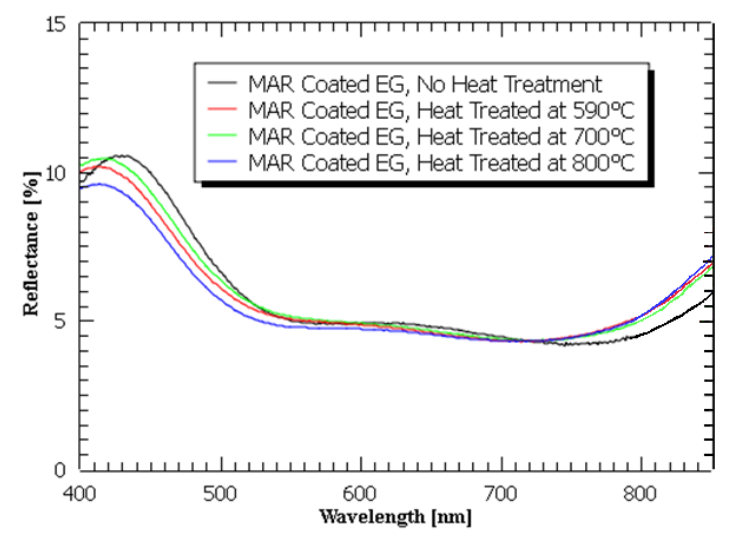

Fig. 13 Measured reflectance spectrum of uncoated glass (black line) MAR coated glass (red line), and MAR coated glass heat treated to $700^{\circ} \mathrm{C}$ (green line) and $800^{\circ} \mathrm{C}$ (blue line), including back surface reflectance.

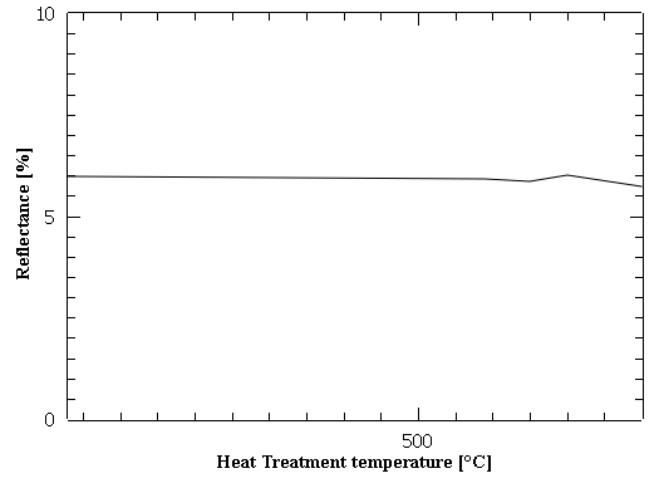

Fig. 14 Plot of heat treatment temperature against WAR of MAR coated Eagle glass. 


\section{CONCLUSIONS}

It is already established that broadband Multi-layer Antireflection coatings can increase the photocurrent of thin film CdTe PV devices by $3.1 \%$ relative [3]. For CdTe modules the glass is the substrate. Ideally, module manufacturers would prefer to source glass with a suitable transparent conductor on one side and a broadband MAR on the other side. For this to be feasible, it is necessary that the MAR coating can withstand the high temperature processes used at various stages during module production.

In this study, we have deposited $\mathrm{ZrO}_{2} / \mathrm{SiO}_{2}$ multilayer coatings on to soda lime glass substrates using pulsed dc reactive magnetron sputtering. We have then exposed the coatings to increasing high temperatures up to $600^{\circ} \mathrm{C}$ for 30 minutes in a muffle furnace for coatings on soda lime glass and up to $800^{\circ} \mathrm{C}$ for samples on Eagle glass. These experiments have enabled us to assess at which point damage occurs and to establish the nature of the damage. For soda lime glass the coatings remained unaffected until the temperature reached $600^{\circ} \mathrm{C}$ with very mild crazing occurring at $590^{\circ} \mathrm{C}$ at the edges of samples where the glass had most warped. At $600^{\circ} \mathrm{C}$ mild crazing of the coating was observed across the entire sample. This is surprising because this temperature exceeds the glass transition temperature for soda lime glass. It appears that the MAR coating remains unaffected until the underlying glass substrate begins to warp. When deposited on High Temperature Eagle glass the coatings appear even more robust, again fissures only appear once the substrate begins to warp at $800^{\circ} \mathrm{C}$ due to the temperature approaching the melting point of the glass.

This is an important observation since it implies that low cost glass can be pre-coated with a high quality broadband anti-reflection coating and the coatings are sufficiently robust to survive exposure to all of the high temperature processes used during thin film CdTe module production. The study has also shown that the Fluorine doped tin oxide (FTO) on the TEC7 also survives the CdTe process temperatures. Hence it is feasible to use Soda Lime Glass with an MAR coating on one side and FTO on the other.

Broadband MAR glass coating using rotating magnetron sputtering processes is already technically feasible. The high volume demand for solar modules relative to other MAR applications could lead quickly to low cost manufacturing at an industrial scale. The implementation of broadband antireflection coatings on glass will result in even more efficient solar modules.

\section{ACKNOWLEDGEMENTS}

The authors are grateful to UKERC for funding through the EPSRC Supergen SuperSolar Hub. They are also grateful to Geraldine Durand, Andy Whitaker and Roger Barnett of TWI for suggestions and guidance.

\section{REFERENCES}

[1] M. A. Green, K. Emery, Y. Hishikawa, W. Warta, and E. D. Dunlop, "Solar cell efficiency tables (Version 45)," Prog. Photovoltaics Res. Appl., vol. 23, pp. 1-9, 2015.
[2] N. R. Paudel, C. Xiao, and Y. Yan, "CdS/CdTe thin-film solar cells with Cu-free transition metal oxide/Au back contacts," Prog. Photovoltaics Res. Appl., vol. 23, pp. 437-442, 2015.

[3] P. M. Kaminski, F. Lisco, and J. M. Walls, "Multilayer Broadband Antireflective Coatings for More Efficient Thin Film CdTe Solar Cells,” IEEE J. Photovoltaics, vol. 4, no. 1, pp. 452-456, 2014.

[4] P. M. Kaminski, G. Womack, and J. M. Walls, "Broadband Anti-Reflection coatings for Thin Film Photovoltaics," in 40th IEEE PVSC, 2014, pp. 2778-2783.

[5] X. Wu, J. C. Keane, R. G. Dhere, C. Dehart, D. S. Albin, A. Duda, T. A. Gessert, S. Asher, D. H. Levi, and P. Sheldon, "16.5\%-Efficient CdS/CdTe polycrystalline thin-film solar cells,” in Proc. of 17th PVSEC, 2001, pp. 995 - 1000.

[6] J. M. Walls and A. G. Spencer, "Hard Coating and the Durability of Anti-reflection coatings," Opt. World, vol. 29, p. 40, 2000.

[7] First Solar, Inc., "Vacuum Deposition System For Solar Cell Production And Method Of Manufacturing," U.S. Patent 20150040970, 02/12/2015.

[8] First Solar, Inc., "Vapor Deposition Apparatus for Continuous Deposition of Multiple Thin Film Layers on a Substrate," U.S. Patent 20150031164, 26/07/13.

[9] U. Schulz, U. B. Schallenberg, and N. Kaiser, "Antireflection coating design for plastic optics.,” Appl. Opt., vol. 41, no. 16, pp. 3107-3110, 2002.

[10]S. Schiller, U. Heisig, and K. Goedicke, "Alternating ion plating---A method of high-rate ion vapor deposition,” J. Vac. Sci. Technol., vol. 12, no. 4, pp. 858-864, 1975.

[11]S. Schiller, U. Heisig, K. Goedicke, K. Schade, G. Teschner, and J. Henneberger, "Advances in highrate sputtering with magnetron-plasmatron processing and instrumentation," vol. 64, pp. 455-467, 1979.

[12]B. Maniscalco, P.M. Kaminski, J.M. Walls, "Thin film thickness measurements using Scanning White Light Interferometry," Thin Solid Films, vol. 550, pp. 10-16, 2014 